\title{
4
}

\section{Addressing Voids: How Digital Start-ups in Kenya Create Market Infrastructure}

\author{
Marissa Drouillard
}

\section{Introduction}

The current chapter will introduce market-enabling digital platforms ${ }^{1}-$ that is, technology companies, particularly start-ups, that are specialized intermediaries providing the necessary information and facilitation for buyers and sellers to do business - as a new lens and frame of reference. The lens will first be applied to several successful technology companies founded in the Northern Hemisphere to show how the framework explains the significance and impact of particular start-ups on the marketplace, including making the underlying mechanics of "disruption" more evident. The lens is then applied to technology start-ups in Southern Hemisphere markets, specifically in Kenya, to illustrate how the same

\footnotetext{
${ }^{1}$ The term is a fusion of "market enablers" from Khanna and Palepu (2010) and various definitions of "platform" as adapted from and expanded by Evans (2009), Brynjolfsson et al. (2006), Bakos (1998), Eisenmann et al. (2006), Baldwin and Woodard (2008), and Rochet and Tirole (2003).
}

M. Drouillard ( $\square)$

Caribou Digital, Cape Town, South Africa

(C) The Author(s) 2017

B. Ndemo, T. Weiss (eds.), Digital Kenya,

DOI 10.1057/978-1-137-57878-5_4 
fundamentals hold true in developing economies. Although ideally, every country would have business-enabling structures and institutions, (e.g., credit bureaus, payment processing systems, and supply chains), unfortunately many developing economies fall short. By building cutting-edge technology companies that create the digital market infrastructure necessary for smooth functioning of markets, emerging market start-ups can create competitive advantages and help enable new waves of entrepreneurial activity and market dynamism.

My understanding of the Kenyan digital entrepreneurship ecosystem is grounded in a study I led in 2013 on behalf of the GSMA Mobile for Development organization and several other development organizations (Drouillard et al. 2014). The study, published in 2014 by GSMA, told the story of the challenges Kenya's digital entrepreneurs face and encouraged stakeholders to increase their collaboration efforts. The overarching questions were: (1) Who are the principal stakeholders in the ecosystem and what are their interests? (2) What is unique and interesting about the emerging population of digital entrepreneurs in Kenya? And (3), What particular challenges do entrepreneurs face in developing and scaling their ventures? Though the study introduced some of the fundamental market infrastructure challenges (especially payment mechanisms), they were not discussed at length. The current chapter picks up this discussion and focuses on the nascent market-oriented dynamics of emerging markets, with an emphasis on Kenya. Core market infrastructure concepts will be introduced and then applied to digital services markets to create the notion of a market-enabling digital platform. Finally, the chapter will conclude with a discussion of why digital platforms have value and significance.

\section{Market Voids}

Kenya is like other emerging markets in that it has persistent challenges that hinder entrepreneurship and economic growth. Frequent financial crises, unreliable quality, and insufficient local talent are often cited as some of the headaches. Khanna and Palepu (2010), however, see such features of emerging markets as "symptoms of underlying market structures that share common, important and persistent differences from those in 
developed economies." The investigators defined the concept of "institutional voids" as missing or ineffective market structures and intermediaries that are the source of higher transaction costs and operating challenges in emerging markets.

Before delving further into Palepu and Khanna's framework describing the types of essential market intermediaries, it will be useful to examine several recent studies that also categorized and quantified business environment voids. From them, we can get an initial sense of the common threads of infrastructure that are necessary to do business in emerging digital economies and how others have been thinking about the importance of market intermediaries - as well as how Kenya benchmarks in these areas regionally and globally.

The World Bank's Doing Business report (2015) is an annual report on the state of health of various economies, based on detailed diagnostics of their underlying and embedded characteristics, such as regulatory systems, the efficacy of the bureaucracy, and the nature of business governance. The report is used by policymakers and businesses to catalyze debate and improve reform. Kenya's overall ease of doing business ranking (1-189, with higher numbers worse) was 108th. The country ranked higher than 100th across all factors except "Getting credit," where it ranks 28th. In spite of a thriving entrepreneurial culture, the country was 151st for ease of starting a business, particularly because of the costs (percent of income per capital) of starting a business and the number of procedures. Indeed, these rankings were not surprising, given Kenya's classification as a lowermiddle-income country (i.e., having annual gross national income per capita of \$1046-\$4125) (The World Bank 2015).

The World Economic Forum's annual Global Competitiveness report (2014) is an analysis of the institutions, policies, and factors that determine the level of productivity of a country and of the country's rates of return and growth. It is an attempt at explaining why some countries are more prosperous than others, prompting discussions at annual gatherings of policymakers, particularly when a country moves significantly up or down in the rankings. The report breaks down determinants of competitiveness into 12 pillars, including institutions, infrastructure, and macroeconomic environment. Kenya ranks 99th out of 140 countries indexed, with an overall score of 3.9 (on a 1-7 scale, with higher numbers 
better). On business sophistication and innovation factors, Kenya ranked relatively high ( $42 \mathrm{nd}$ out of 140 ). On basic requirements (institutions, infrastructure, macroeconomic environment, health, and primary education), however, it ranked poorly (116th out of 140). The low scores on basic requirement factors were significant, given that infrastructure and institutions are cornerstones for markets to function.

Boston Consulting Group's eFriction report looked at how certain factors inhibit consumers and businesses from fully participating in the Internet economy, thereby constraining economic activity (Zwillenberg et al. 2014). The report was significant in that it attempted to define the factors driving economic growth caused by having a more digital economy. The four categories of voids discussed in the report were: (1) infrastructure-related, limiting basic Internet access; (2) "industry" sources (e.g., workforce ICT skills, trade barriers, access to capital, and the strength of intellectual property protection), affecting the ability of companies to maintain an Internet presence and engage in online transactions; (3) "individual" sources, constraining consumer Internet activity; and (4) information-related voids affecting the general availability of, and access to, online content - have some overlap with the framing used by Palepu and Khanna. Countries were scored on a 0-100 scale, using indicators selected for each of the four categories. Higher scores denoted higher levels of eFriction; an overall score and ranking were also calculated (better rankings aligned with lower scores). Across the four areas, Kenya ranked 64th in Infrastructure, 50th in Industry, 48th in Individual, and 33 rd in Information, ranking the country 57th overall (of 65 countries profiled) and in the highest quintile of countries analyzed. It is interesting to consider Kenya's much higher ranking in Information versus its lower rankings in other areas (which, given the findings in the previous studies, are not surprising). What appeared to be driving this was the level of open encyclopedia pages in home languages, number of micro-messages made in home languages, and freedom on the Net.

Finally, the Global Entrepreneurship Index (GEI) report looks at the entrepreneurial ecosystem of a country, combining individual data with institutional components (Acs et al. 2015). The GEI is made up of three sub-indexes (Attitudes, Abilities, and Aspirations), each composed of several pillars. Kenya ranks 86th out of 130 countries studied by the index, and 5 th out of 29 countries in Sub-Saharan Africa. Its 
areas of best performance were Competition, Opportunity Perception, and Internationalization; the areas of worst performance were Process Innovation, Technology Absorption, and Risk Capital. Indeed, the poorperforming areas reflect the fact that fundamental intermediaries in capital markets and basic modern infrastructure necessary for product markets are still developing in Kenya. Moreover, it is not surprising that Opportunity Perception was high, given that there are currently many voids across a number of sectors.

\section{Market Enablers}

There are some accepted categories, or types, of market enablers that can fill the voids outlined above. In Khanna and Palepu's book Winning in Emerging Markets (2010), the authors listed several basic market-enabling institutions required for any market (capital, products, labor, etc.) to function ${ }^{2}$ :

- Credibility enhancers are institutions that independently certify qualifications or claims made by suppliers or consumers. Examples include auditors, who certify that a business has adequately reflected its state of affairs in accounting documents, and Kenya Bureau of Standards marks of standardization and excellence, which certifies that a product meets specific criteria.

- Information analyzers and advisors are institutions that collect or analyze information about suppliers or consumers. Examples include credit rating bureaus, which provide information to finance institutions and others about business or consumer credit-worthiness, and market research organizations, which review products and provide decision-making guidance.

- Aggregators and distributors, probably the most fundamental type of market institution, work to match supply and demand. Examples include banks, which aggregate supplies of money (e.g., savings

\footnotetext{
${ }^{2}$ Khanna and Palepu (2010) introduced six institutions in the book-the four identified here in addition to regulation and adjudication. However, given that the latter two are government- and parastatal-led, rather than private-sector led, they are not discussed in this chapter.
} 
accounts) and make money available for consumers who need cash, and mass retailers such as Game, which aggregates many different consumer products and sells them to customers through its chain of stores. ${ }^{3}$

- Transaction facilitators are institutions that make it possible for exchanges to take place, typically money for information, goods, or services. Examples include stock exchanges, credit card issuers such as VISA or MasterCard, and mobile money wallets such as M-PESA.

Market enablers are readily available in most advanced economies. Auditors, for example, enhance the credibility of companies seeking finance by certifying the companies' solvency. Enterprises can turn to management consultants or technology product reviews when evaluating a new human resources system. And various credit card issuers and payment-gateway infrastructures exist to transact seamlessly with customers. The existence of market enablers also improves the prospects for new entrants entering the marketplace by reducing barriers (such as information, distribution channel, geographical, and other barriers). In this regard, the international grocer Whole Foods has helped both new companies and new products reach scale on the back of its reputation. Through its regional program, the organization regularly reviews potential new products, trialing them in stores and regions and sometimes helping small producers expand their operations (Whole Foods Market 2016). Likewise, payment-processing company PayPal has enabled any business (or individual) to transact or collect payments on eBay without having to handle cash or be present in the same room as the buyer.

In emerging markets, however, market enablers are nascent-fewer organizations play enabling roles, specific types of market functions are not present, and in some markets, organizations are present but ineffective in their role as an enabler (e.g., a government institution that register businesses using a process that takes multiple months). These challenges are what Palepu and Khanna referred to as "voids," and because such gaps exist, businesses and consumers experience information asymmetries as well as uncertainty, resulting in a higher cost of doing business. To

\footnotetext{
${ }^{3}$ Game is the flagship store for South African Massmart, now majority-owned by US giant Wal-Mart.
} 
illustrate the point, compare the process for obtaining financial services as a small business or start-up. In the UK, after completing an application online and submitting paperwork with a signature and proof of address, HSBC (a leading personal and business retail bank) creates an account and issues a business credit card. By contrast, many of the startups interviewed for my Kenya study (Drouillard et al. 2014) faced challenges accessing any kind of financing, particularly from banks. Indeed, stringent requirements (cited by $31 \%$ of respondents) and high interest rates $(8 \%)$ were reactions by banks to information asymmetries-for example, if creditworthiness is uncertain or costly to obtain, then the banks must charge more and demand more significant collateral, such as property titles.

\section{Special Type of Market Enabler: A Digital Platform}

There is significant variation in what gets called a "digital platform"from software (e.g., Microsoft Windows, Amazon, and Uber) to business archetypes (e.g., software as a service and advertising networks). Some of the key aspects of digital platform businesses that academics have discussed include highly efficient matching and large ecosystems of complementary products and services. ${ }^{4}$

Indeed, digital platforms are special types of market enablers, and there are characteristics common to large-scale and often-disruptive digital businesses that distinguish them from other technology start-ups:

First, digital platforms tend to enable a two-sided marketplace. A two-sided (or multiple-sided) market refers to two (or more) distinct user groups that transact through the market. Importantly, the value for people in one group is dependent on the number of people in the other group. The more developers are creating apps on iOS for the Apple App Store, for example, the more attractive iPhones are for consumers. And the more merchants accept American Express, the more valuable

\footnotetext{
${ }^{4}$ The definitions of "platform" were adapted from Evans (2009), Brynjolfsson et al. (2006), Bakos (1998), Eisenmann et al. (2006), Baldwin and Woodard (2008), and Rochet and Tirole (2003).
} 
AmEx cards are for consumers. ${ }^{5}$ Furthermore, their operating models both depend on and benefit from network effects, in which the value of the company increases with the size of the user base (both suppliers and consumers). For example, as more drivers onboarded on Uber's platform, wait times decreased for customers, making the service more valuableand as more customers shifted to Uber for rides, profit-making opportunities for Uber drivers increased. Moreover, digital solutions also have a comparative advantage in scaling networks, because once core network infrastructure and software have been deployed, there is typically a very low marginal or incremental cost for adding another user.

Second, digital platforms tend to enable digital marketplaces by providing multiple functions, and digital marketplaces enable exchanges for physical or digital goods (e.g., eBay and most of Amazon). All digital markets are great at connecting otherwise hard-to-coordinate buyerseller relationships and enabling search and discovery, allowing a much broader range and diversity of participation by buyers and sellers and thus of transactions (e.g., the long tail).

Third, digital platforms tend to offer an improved, more seamless service to the customer than incumbents or competitors, typically by combining multiple market-enabling functions. Uber, for example, matches customers with ride providers and collects payment through its mobile app, and AirBnB makes it easy for customers to search for and book stays in other people's houses by showing possible units that are available for the desired stay period while sharing reviews by other guests and collecting payment.

Fourth, in addition to providing a better value proposition for customers, digital platforms tend to create ripple effects in supplier ecosystems. Amazon in the UK, for example, engages many local companies to provide expedited last-mile delivery to customers. Having now built the coordination processes and technology necessary to manage such deliveries, the more that Amazon is able to stimulate online purchases, the greater the opportunity for the local delivery companies. Uber cars, similarly, must meet certain quality standards (e.g., cleanliness and model year), which increase business for, for example, car washes.

\footnotetext{
${ }^{5}$ It is important to note that, although these examples are all two-sided markets, they are not all platforms.
} 
Finally, digital platforms may eventually become "software platforms," enabling further ecosystem innovation. A software platform usually refers to a core technology that can be extended in innovative new ways by external parties. The platform owner typically controls it (either through the user interface or the application program interface [API]) but relies on external parties to innovate, adding value to the entire ecosystem around the software platform. Examples include Google Android, Sony PlayStation, and Force.com.

In the current chapter, I refer to this unique class of digital technology ventures as market-enabling digital platforms-entrepreneurs' response either to voids or to opportunities to improve the current system. Indeed, across all markets and entire economies, market-enabling digital platforms are replacing traditional analogues (e.g., Uber displacing taxis or Amazon disrupting Barnes \& Noble-indeed, this is one form of industry disruption) or creating new infrastructure where voids existed previously. The sections that follow will describe several examples of digital platforms in Northern Hemisphere economies and in Kenya, discussing the characteristics that make them market enabling.

\section{Market-Enabling Digital Platforms in Northern Hemisphere Economies}

When digital platforms disrupt the status quo in an advanced market, they capitalize on the fact that what was considered well-functioning was not, in fact, market clearing ${ }^{6}$ : incumbents were limited by capacity, geography, or territory, among other factors. An example is how AirBnB disrupted the traditional hotel industry by making it easier for people who wanted to rent out their house or room to do so and by making it easier for those who were interested to search for and book stays. Digital platforms also have the effect of redistributing the power and control that incumbents had in the marketplace. Even in so-called well-functioning markets, a certain amount of information asymmetry or inefficiency allowed some stakeholders to profit, sometimes at the expense of consumers. When digital technology solutions disrupt existing markets, the

\footnotetext{
${ }^{6}$ Market clearing means that there is no leftover supply or demand.
} 
centers of power that were reinforced by information asymmetries shift to platform owners, who now provide the information that incumbents withheld, capturing value often in a very different way.

Consider the real estate market as an example. In advanced economies, real estate agents, property assessors, escrow finance institutions, and others facilitate a property transaction. When real estate agents controlled access to information about the marketplace-the properties that were available for sale, how much a property might sell for, and so on-home seekers were at their mercy, and the agents enjoyed significant transaction fees. The Internet disrupted the real estate market by introducing independent real estate listing services, such as Craigslist, where sellers could self-promote property for sale or rent and home seekers could declare interest in a particular market. Although Craigslist does not explicitly match buyers to sellers, its ability to aggregate supply and demand partially replaced the need to find listings via a real estate agent. Other real estate listing services, such as Trulia $^{7}$ and Zillow, ${ }^{8}$ provide additional information that was not easily available for independent buyers and sellers before, such as when the property was last sold, comparisons across the neighborhood, crime statistics and incidents, and dates of open houses. But they also develop and protect a new set of data about their users and users' behavior online as well as information about mortgages and other third parties that the site directs users to. These data become the new information asymmetry, creating competitive advantages.

There are many other examples of market-enabling digital platform businesses (that were once start-ups) in advanced economies that have disrupted markets for products or services. Table 4.1 below shows several success stories, describing the two- or multi-sided markets involved (e.g., consumers, publishers, and specialized service providers), the marketenabling functions of the business model (e.g., credibility enhancer, information analyzer and advisor, aggregator and distributor, or transactions facilitator), how the business addressed deficiencies in the marketplace (e.g., transaction friction and relevance to customers), and the analogue that was disrupted (bricks-and-mortar stores, paper catalogs, etc.). The

\footnotetext{
${ }^{7}$ See www.trulia.com for additional information.

${ }^{8}$ See www.zillow.com for additional information.
} 


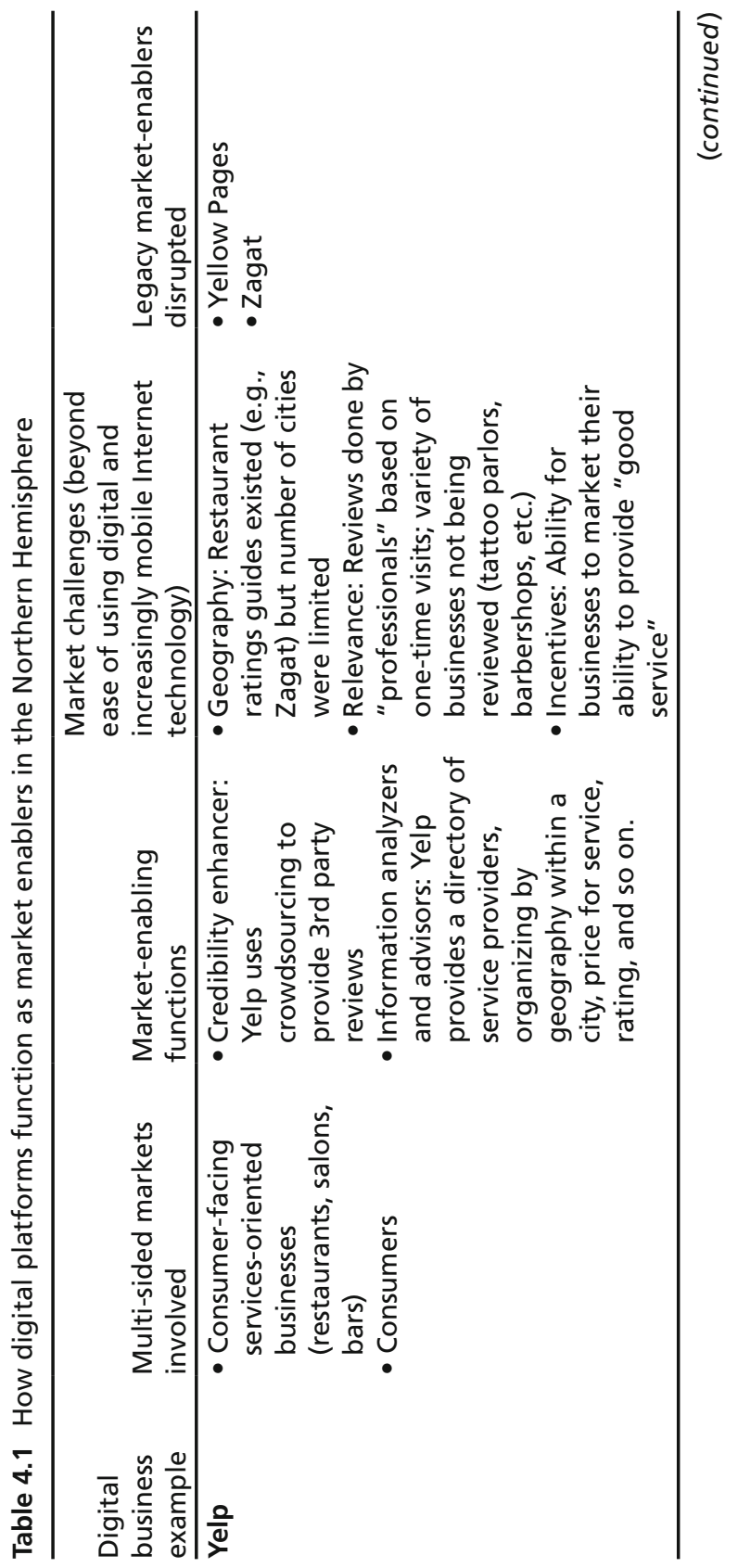




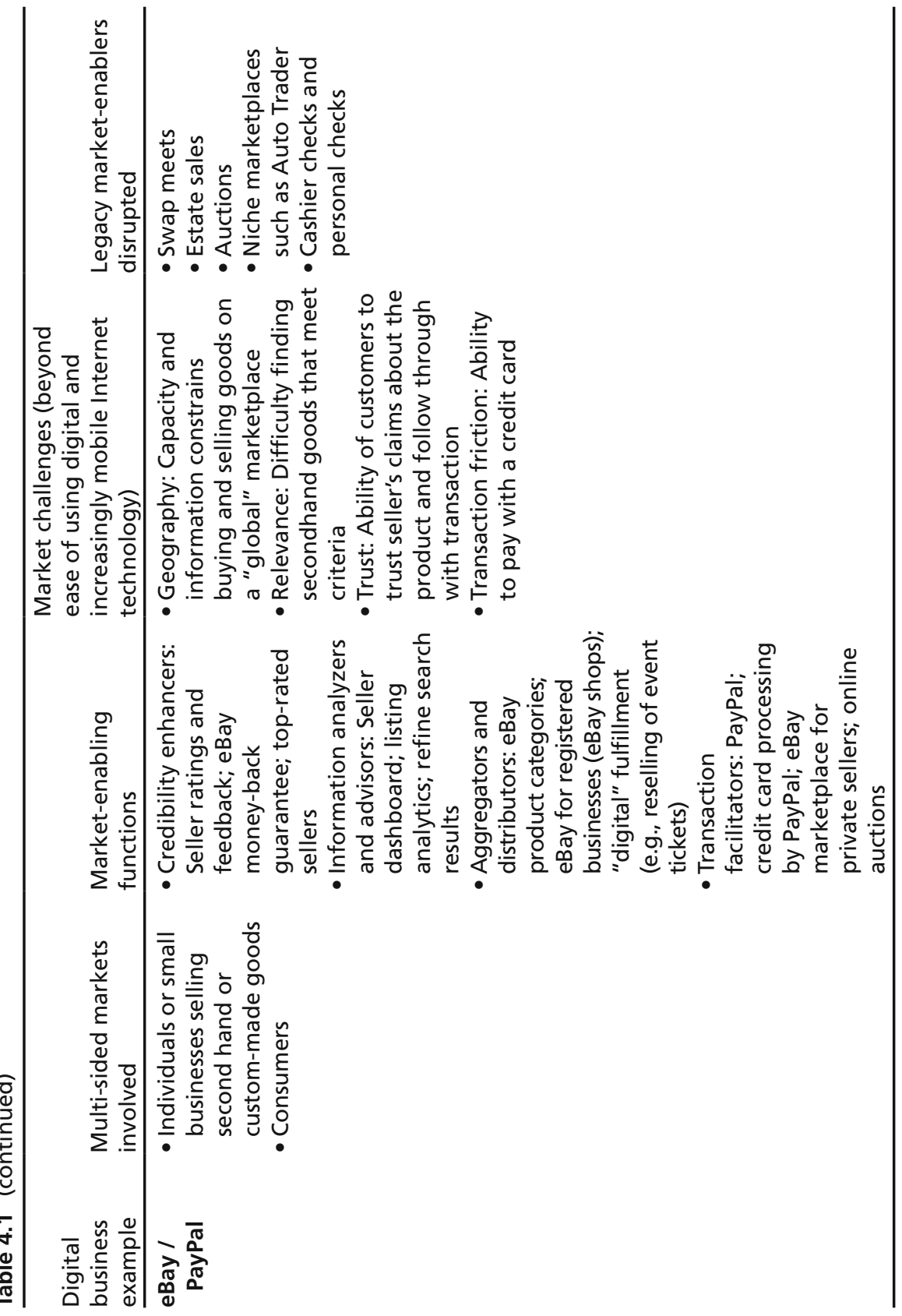




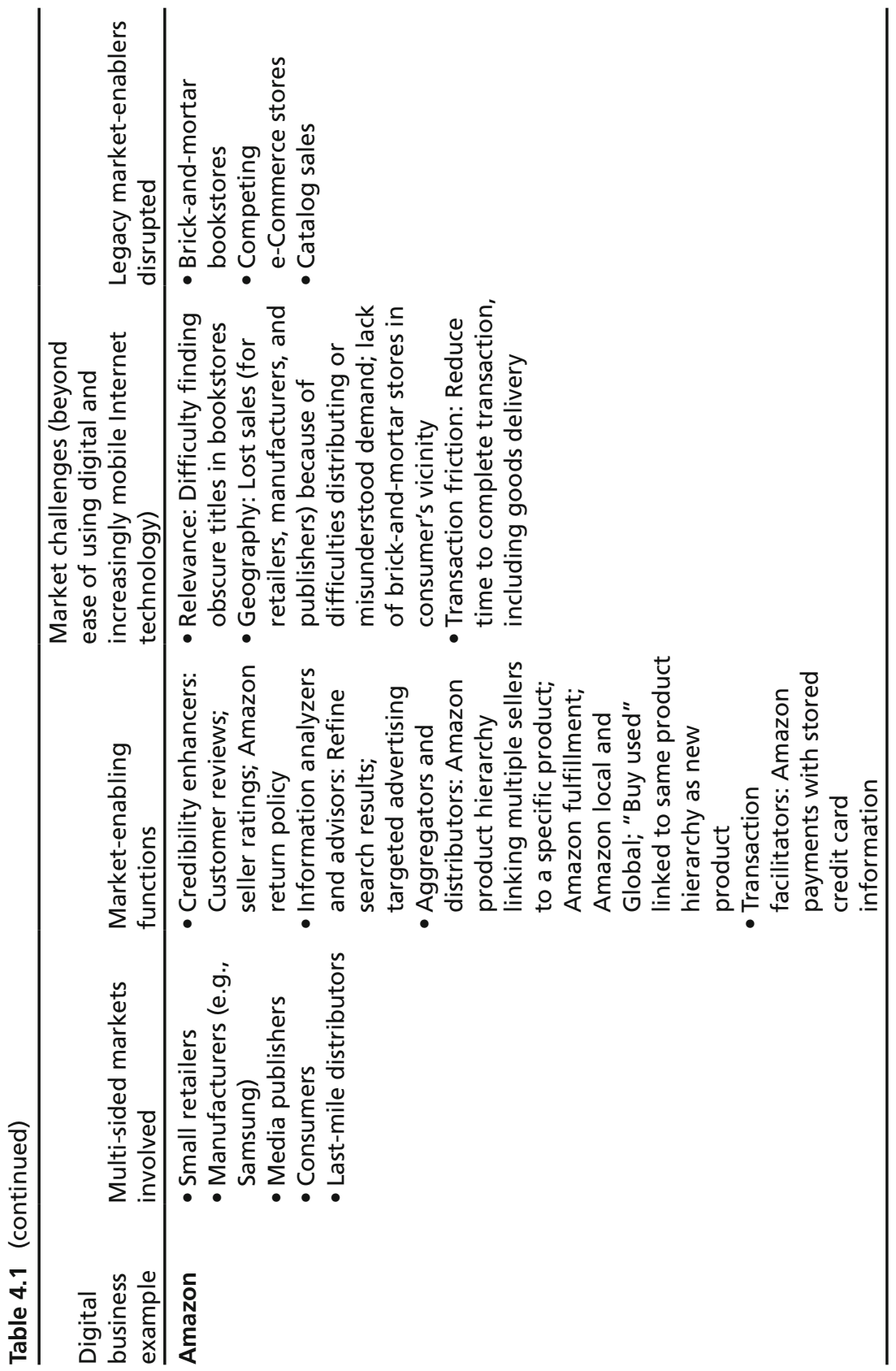




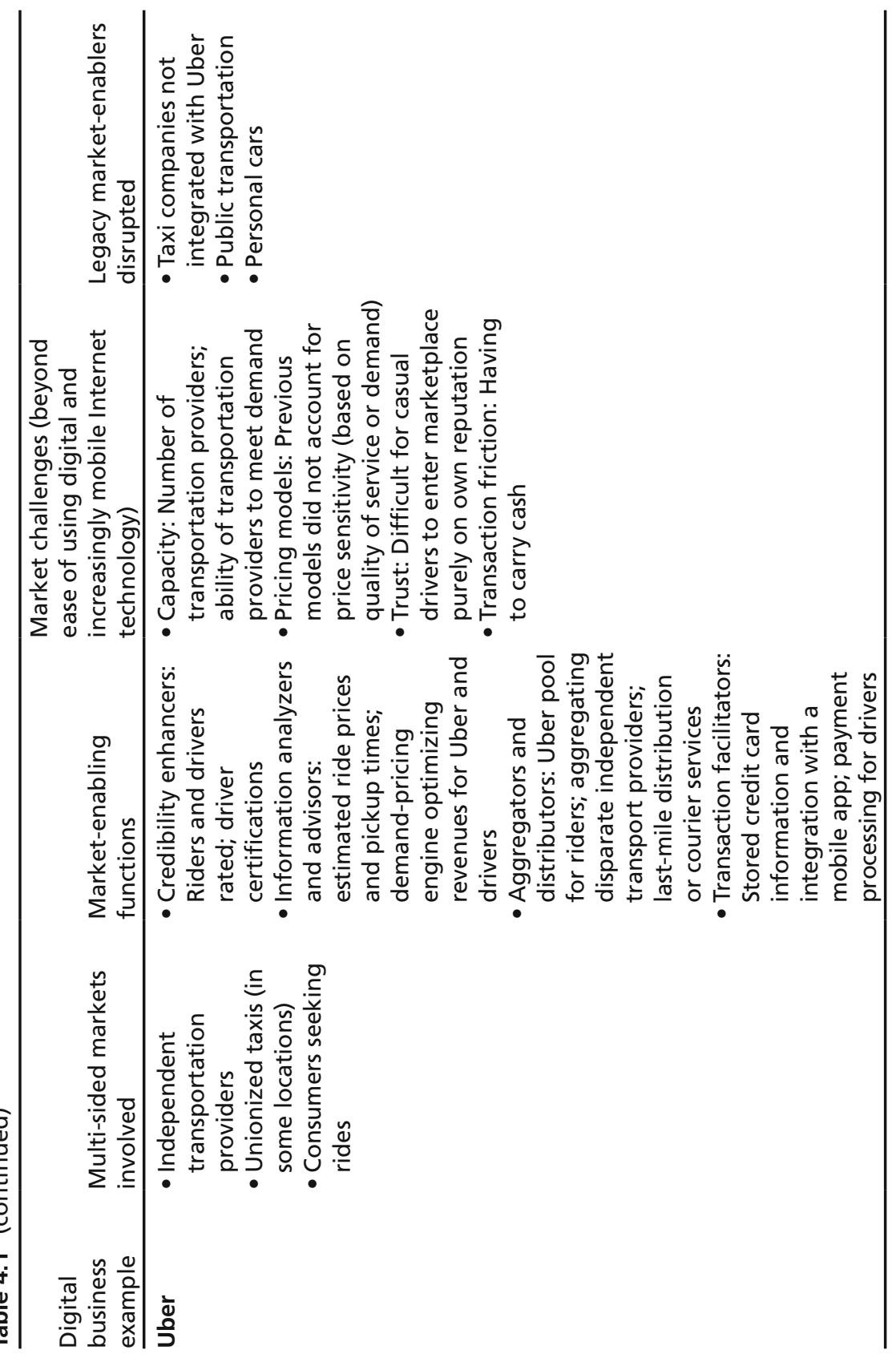


examples were identified from a list of "unicorn start-ups" (i.e., start-ups with a valuation of USD1 billion or greater).

One such example is Yelp, which provides online directories of service providers together with crowdsourced reviews. Although reviews and guides did exist for high-end restaurants (e.g., Zagat), for example, the vast majority of other service providers were lauded or lamented via word of mouth. Yelp solved the challenge of geography, because any restaurant anywhere could be added to the directory and reviewed; the challenge of relevance, because the reviews are written by everyday people and include a wide variety of businesses that people use, such as barbershops and salons; and finally, the challenge of incentives, giving service businesses the ability to market their ability to "provide good service." In this respect, Yelp functions as a credibility enhancer (via the crowdsourced reviews) and an information analyzer and advisor (through its directories, which have filtering functionality to aid decision-making).

eBay is a digital platform that fills all of the market-enabling functions. It has credibility enhancers that help sellers with positive feedback and large volumes of transactions to sell out. Ebay's money-back guarantee also enhances the credibility of merchants selling through the platform, especially because some portion of the goods sold are used. Many tools are provided that help analyze information for both buyers and sellers. Buyers are able to refine search results and locate very specific items or a range of items that meet their criteria. Sellers benefit from dashboards and analytics to help increase sales. eBay is also an aggregator and distributor, innovating with standard product categories to help customers look at products across a number of "stores," and a digital fulfillment service (in, e.g., the reselling and distribution of event tickets). As a transaction facilitator, eBay's credit card processing capability (through PayPal) enables the consummation of transactions, and its online auctions provide a unique way for private sellers to unload items when they are not sure of the value.

Similarly, Amazon also fills all of the market-enabling functions in similar ways. As a credibility enhancer, Amazon shares customer reviews and seller ratings and offers a flexible return policy. As an information analyzer and advisor, its search and refine capabilities are similar to eBay's.

\footnotetext{
${ }^{9}$ See www.cbinsights.com/research-unicorn-companies for a complete list of unicorn start-ups.
} 
However, Amazon also has targeted advertising capabilities, which means it is mining and extracting value from information about customer searches and purchases. Its core feature is the ability to find anything online-aggregating and distributing products that effectively enable a global marketplace. Finally, Amazon's stored credit card information and one-click checkout facilitate transactions by making it easy for Amazon shoppers to make purchases at any time.

More recent unicorn Uber also fills all of the market-enabling functions of a digital platform. Both riders and drivers are rated through the App, enhancing the credibility of people who are otherwise strangers. The company also has several information analyzer and advisor features for its network of riders and drivers: Its demand pricing engine uses information about demand and supply to optimize revenue for Uber and its drivers. In addition, the estimated price of rides and length of journeys is now integrated into Google Maps route queries in some cities. Its key feature is being an aggregator and distributor, matching independent transport providers with customers seeking rides; it also aggregates disparate riders into pools for carpooling and lower fares for each individual. Finally, the company facilitates transactions by billing riders via stored credit card details and paying drivers on a weekly basis.

\section{Market-Enabling Digital Platforms Emerging in Kenya}

Digital platform businesses emerging in Kenya share the same characteristics as successful ventures in Northern Hemisphere economies, but the role that they play varies. In more advanced economies, the companies mentioned earlier achieved success by replacing incumbents with their own platforms. In Kenya, the business environment is still nascent, and as revealed by the reports discussed above, infrastructure is a challenging area. However, with fewer incumbents, there are also more opportunities for new players. Several start-ups that have achieved some success have done so by creating digital infrastructure where none had existed previously (or where it was so ill-equipped that it might as well have been nonexistent). 
One such example is Cellulant, ${ }^{10}$ a transactions facilitator, aggregator, and distributor, that was founded in 2004 by Ken Njoroge ${ }^{11}$ after he realized that mobile payment infrastructure was lacking in Kenya and that it was affecting his music downloads business. The company focused first on connecting banks, and eventually, mobile operators, enabling customers to pay directly for goods or services via their mobile phones. As Ken said during an interview in 2013, "We became very efficient at laying pipes" (Drouillard et al. 2014). Cellulant currently provides digital financial services in ten countries in Africa (Kenya, Tanzania, South Africa, Ghana, Rwanda, Botswana, Zambia, Ethiopia, and Mozambique). Ken now sees his business as a connector of digital wallets (whether mobile operators, banks, or independent entities) and marketplaces, enabling interoperability and payments among various banks and mobile operators-making Cellulant one of the broadest transaction facilitators in Kenya.

Cellulant's model shares some of the same characteristics that were highlighted in successful Northern Hemisphere digital ventures. The financial transactions marketplace that Cellulant's technology enables is multisided, connecting merchants or businesses with digital currency issuers (banks and mobile operators) and consumer wallets. Network effects enhance Cellulant's offering in that the more connections Cellulant has with merchants and businesses, the more valuable the company is to digital money issuers, and vice versa. There were core infrastructure challenges, in that banking infrastructure and systems in Kenya were not prepared for mobile commerce, especially in 2004. Even after M-PESA launched, integration between mobile operators and banks and businesses still needed to happen. Cellulant built technology to manage reconciliations and aggregate financial transactions, particularly transfers and payments, functioning as an aggregator and distributor in the marketplace for mobile financial transactions. As systems matured, Cellulant's technology facilitated transactions between consumers and businesses by making it possible and seamless to use a mobile device to pay bills and perform banking tasks. As an early pioneer in architecting and building a mobile financial ecosystem in Africa, Cellulant's solution has certainly had an impact.

\footnotetext{
${ }^{10}$ See www.cellulant.com for additional information.

${ }^{11}$ See "Conversation with Ken Njoroge: How to Be a Rebel and Build a Business at the Same Time" in this book for additional information.
} 


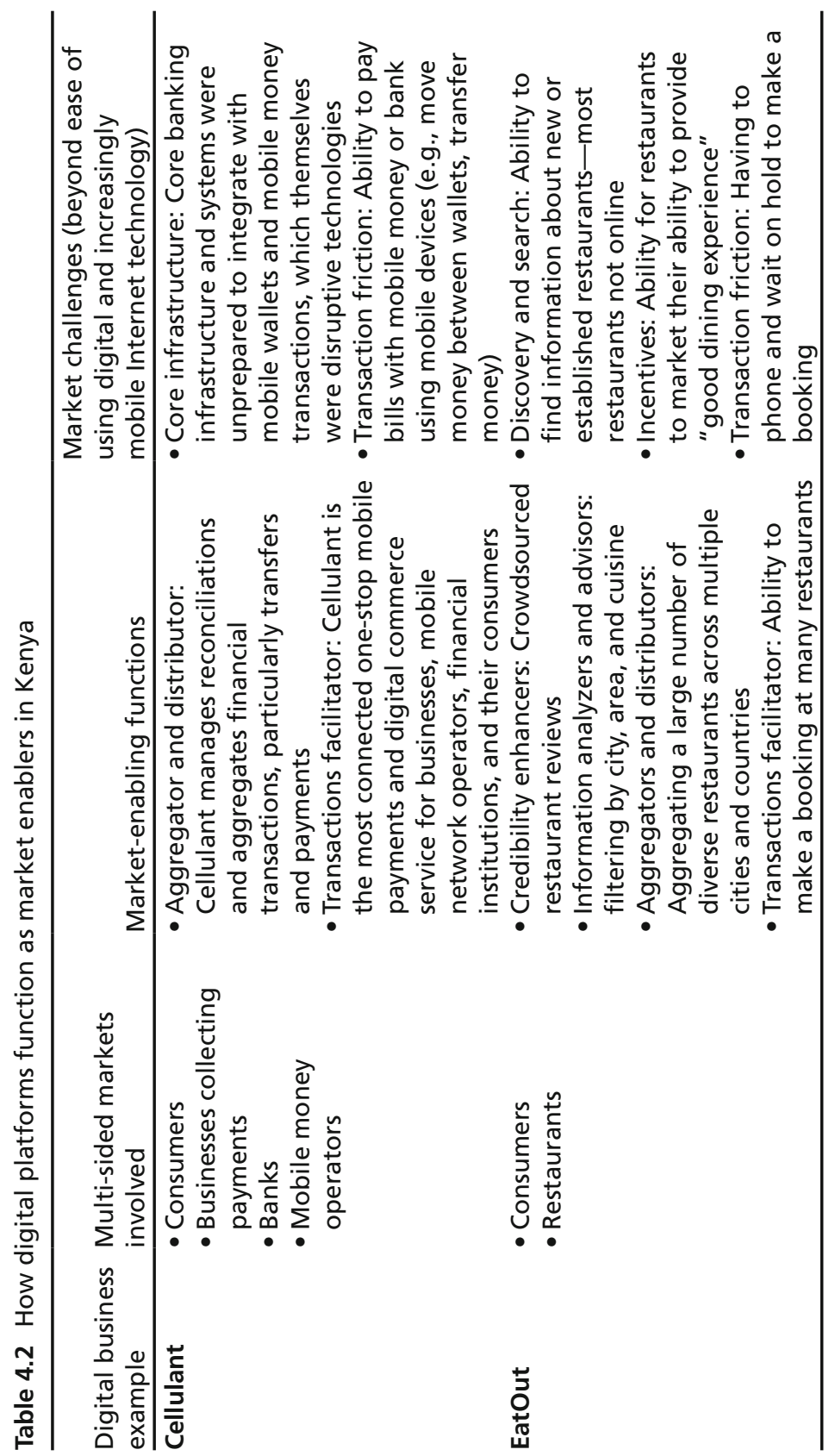




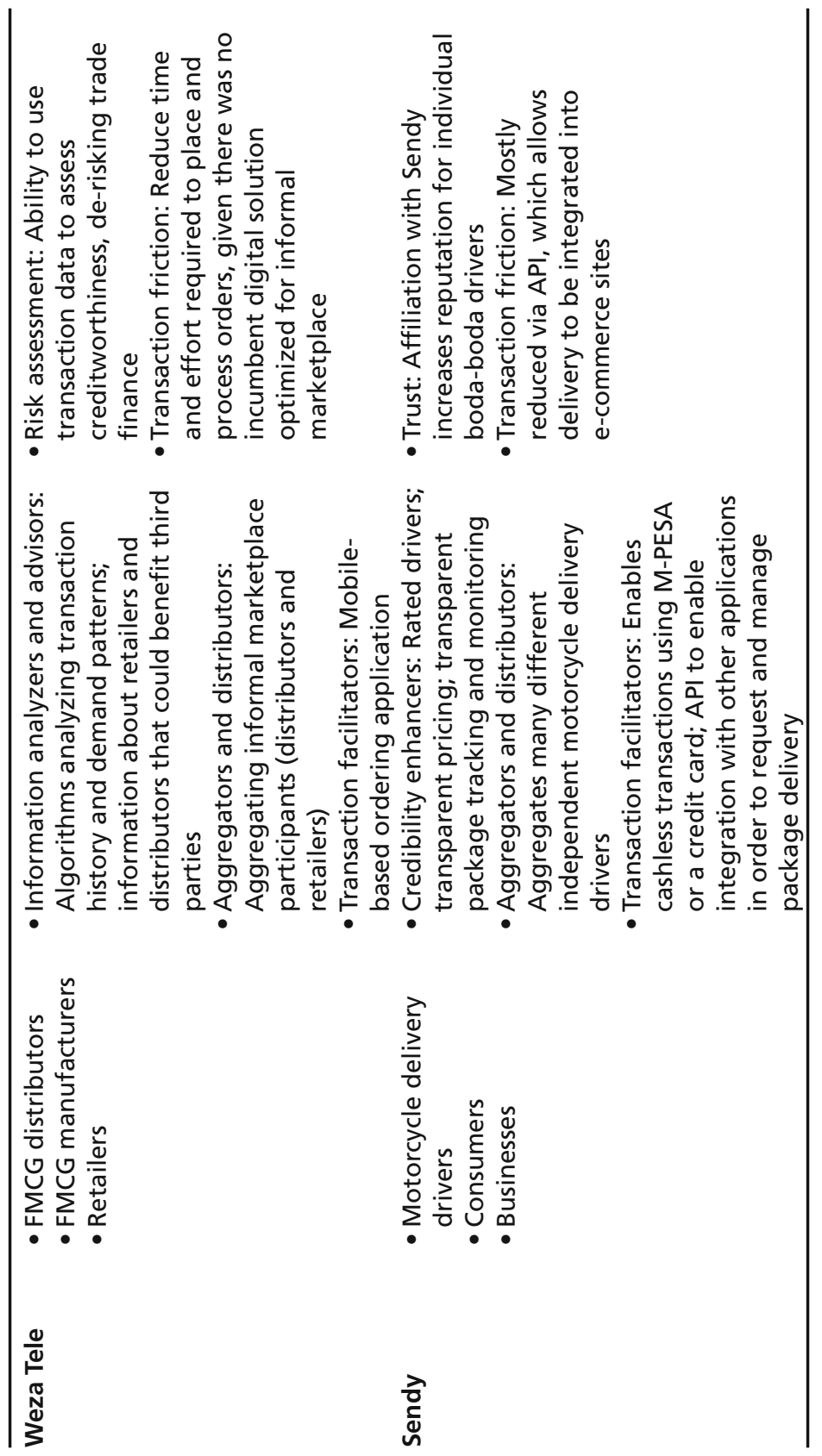




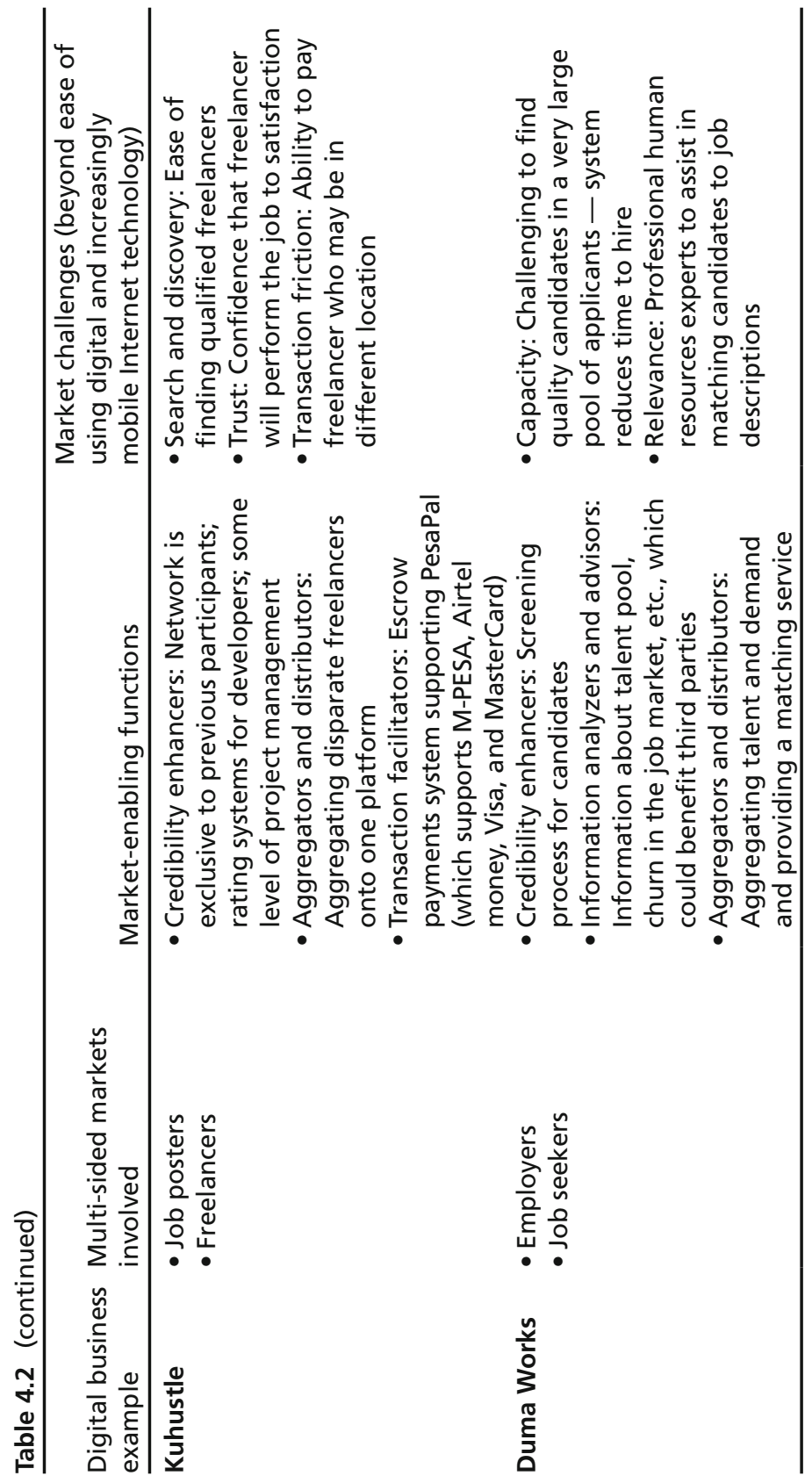


The company's integration products are enabling further innovation, such as mobile banking products for farmers linked to integration and analytics provided by the company (TechMoran 2015).

There are, in fact, many start-ups developing market-enabling digital platforms in Kenya. Brief profiles for several that have attracted investment and attention follow below, with an explanation of how they function as platforms in Table 4.2 .

\section{EatOut $^{12}$ : Restaurant Review and Booking Platform}

EatOut, founded in 2010 by Mikul Shah ${ }^{13}$, provides a directory with crowdsourced reviews of local restaurants in addition to a booking engine. The idea for the start-up stemmed from Mikul's observation of the gap in the marketplace for comprehensive restaurant information in Nairobi. EatOut helps restaurants ranging from tiny neighborhood cafés to top tables to engage with diners, and it helps diners find their next meal. The company is solving the challenge of discovery and search by making it easy for diners to hear about new or established restaurants. In fact, most restaurants in Kenya, even in Nairobi, are not online. EatOut enables them to have an online presence and be discoverable. Its crowdsourced reviews enhance the credibility of restaurants and create incentives for good service. For a select number of restaurants, bookings can be made online, reducing the transaction friction of having to wait on hold to speak with a host. EatOut is backed by Netherlands-based venture capital fund Africa Media Ventures Fund and has plans to scale across Africa.

\section{Weza Tele ${ }^{14}$ : Digitizing Supply Chains}

Weza Tele was co-founded by Hilda Moraa after a university internship revealed an opportunity to improve the fast-moving consumer goods (FMCG) supply chain system in Kenya. There are many small retail shops and kiosks in Kenya that sell FMCG products, such as Coca-Cola, water,

\footnotetext{
${ }^{12}$ See eatout.co.ke for additional information

${ }^{13}$ See "Conversation with Mikul Shah and Ritesh Doshi: The Hustling Entrepreneur on Trial" in this book for additional information.

${ }^{14}$ See wezatele.com for additional information.
} 
and shampoo. Because the informal supply chain is not yet digitized (i.e., retailers do not have electronic point-of-sale systems or computers and technology to keep stock and place orders electronically), store owners end up wasting valuable time standing in lines at distributors. Furthermore, a lack of digital recordkeeping makes it difficult for shops to prove creditworthiness. Building an easy-to-use ordering platform using basic mobile technology, Weza Tele was able to increase visibility to demand patterns for retailers and relieve pain points for distributors (Moraa 2015). By analyzing transaction histories, Weza Tele was able to provide summary information to retailers about the performance of their distributors. Weza Tele was acquired by AFB, a financial services institution that uses data to understand customer behavior and provide unsecured credit digitally.

\section{Sendy ${ }^{15}$ : Optimizing Pick-up and Delivery}

Sendy, founded in 2014 by Alloys Meshak, is an Uber-style motorbike delivery service that lets customers book, track, and pay for deliveries directly from mobile phones. The platform aggregates and distributes demand for deliveries by matching requests from customers with the company's network of crowdsourced delivery couriers, who also leverage the company's enhanced location and route planning intelligence (Wakoba 2015). As noted by the company's COO Maliaka Judd, "We are not a courier business. Everyone thinks we are... but actually we are a marketplace for courier providers. Anyone who wants to do deliveries and passes our vetting process can 'sell' through our platform. Whether you're on foot, ride a bicycle or a motorbike, drive a van or a pickup, manage a fleet of vehicles, or fly a plane... if you want to sell your services through Sendy - we're happy to have you! We're not trying to rebuild the existing vehicle/courier infrastructure. We're trying to optimize and aggregate it to make it more transparent and efficient" (White 2015). Sendy is an example of a company in the e-commerce ecosystem, because online shops such as Jumia and OLX depend on distribution and lastmile delivery service providers.

\footnotetext{
${ }^{15}$ See api.sendy.co.ke for additional information
} 


\section{Kuhustle $^{16}$ : Job Matching for Freelancers}

Kuhustle brings together several interesting platform functions, including being a transactions facilitator through its freelance job listing and bidding and escrow payments system and enhancing the credibility of bidders and job posters by making the network exclusive. Everyone who joins Kuhustle gets three invitations to share with other people; if the invited person posts jobs or delivers work, then a percentage of the value of the job is given as a bonus. Kuhustle boasts over 2000 freelancers on its network and over kenyan shillings (KES) 1,000,000 in jobs.

\section{Duma Works ${ }^{17}$ : SMS-Based Talent Matching}

Duma Works connects growing companies to talent via an SMS-based job-matching platform that ensures quality through a screening process. The platform is enabling the marketplace for talent by enhancing credibility through its screening process and by aggregating talent and matching it with demand for skilled resources from various businesses. Founded in 2012 by Arielle Sandor and Christine Blauvelt, Duma Works was the winner in the Enterprise category at 2015 Pivot East. The company currently has over 22,000 job candidates and 200 employers registered on the system, and has matched over 5000 jobs, with an average time-to-hire of 10 days.

\section{Conclusion and Recommendations: The Impact of Market-Enabling Digital Platforms}

Although there are impact investors and donors who actively invest in and otherwise support start-ups in developing-world markets, many questions have been raised about the theory of change behind these activities. Although there are many possible ways that start-ups contribute to economic development, we have aimed this chapter to shed light on how digital platforms create and enhance market infrastructure and

\footnotetext{
${ }^{16}$ See www.kuhustle.com for further information.

${ }^{17}$ See www.dumaworks.com for further information.
} 
intermediaries. The examples from both the Northern Hemisphere and Kenya have shown that this framework is applicable to emerging markets and has considerable power as a paradigm for evaluating start-ups with potential to have significant impact.

Particularly powerful digital platforms not only solve a direct problem, or fill a void, but also, by doing so, help to develop the overall market ecosystem so that other products and services can also flourish. A great example of this is how Cellulant is enabling an ecosystem of financial services products for businesses and consumers through the services it provides as a transactions facilitator and aggregator. This includes not only banks and other institutions leveraging Cellulant's capabilities to build mobile banking applications but also unlikely innovations such as eWallets for farmers in Nigeria. Additionally, Sendy's Uber-like delivery marketplace is making e-commerce in Kenya tangible and even streamlined through its API, which can request and track deliveries.

Digital platforms having similar ecosystem-enabling effects are also emerging in other Sub-Saharan African countries. For example, Where Is My Transport ${ }^{18}$ is a South African start-up that is optimizing the transportation system in major emerging-market metros. Its market-enabling functions include being an aggregator and distributor of public and private transportation services and analyzing information for private transport providers and transport authorities. It has created a marketplace for informal and diverse transportation providers, such as taxis and municipal bus systems, and for public transport riders. Its solution is already enabling Cape Town's myCiTi bus service to optimize routes and improve bus stops through more intelligent information about riders' desired beginning and end points. Another example, expressPay, ${ }^{19}$ is one of many Ghanaian start-ups working to improve the payments ecosystem. The national payments system in Ghana is still very nascent, and interoperability challenges make it difficult for merchants to adopt digital payments. expressPay aggregates various methods of payment (mobile money, credit cards, and debit cards) and facilitates transactions through its smartphone app and technology-and-productivity solution. Other

\footnotetext{
${ }^{18}$ See www.whereismytransport.co.za/ for further information.

${ }^{19}$ See www.expresspaygh.com/index.php for further information.
} 
start-ups can then leverage expressPay in their own solutions, whether they are e-commerce marketplaces or tablet-based point-of-sale systems for small retailers.

In summary, the potential for digital start-ups in emerging markets to enable marketplaces for financial services, products, capital, and so on, and even for entire ecosystems is extraordinary. In Kenya, there are still opportunities to reduce transaction costs in digital payments, possibly through bitcoin and blockchain solutions. Furthermore, trade finance and credit for small businesses in informal markets are still major areas of opportunity. Companies that can develop algorithms to assess creditworthiness based on alternative information, such as mobile phone top-ups, can play a significant role as information analyzers and advisors. Digital identity solutions, perhaps enabled via blockchain, could increase the credibility of local job candidates in a global marketplace for talent as well as reduce the costs and corruption in providing government services. Finally, resolving voids in aggregation and distribution, especially in agriculture supply chains, will have a significant impact on market functioning and attractiveness and offer benefits for the economy as a whole.

\section{References}

Acs, Z., Szerb, L., \& Autio, E. (2015). Global entrepreneurship index 2015. Washington, DC: The Global Entrepreneurship and Development Institute. Bakos, Y. (1998). The emerging role of electronic marketplaces on the Internet. Communications of the ACM, 41(8), 35-42.

Baldwin, C., \& Woodard, C. (2008). The architecture of platforms: A unified view. Harvard Business School, HBS working paper number: 09-034, 10 October.

Brynjolfsson, E., Hu, Y., \& Smith, M. (2006). From Niches to Riches: Anatomy of the Long Tail. MIT Sloan Management Review, 47(4), 67-71.

Drouillard, M., Taverner, D., Williamson, C., \& Harris, M. (2014). Digital entrepreneurship in Kenya. London: GSMA.

Eisenmann, T., Parker, G., \& Van Alstyne, M. (2006). Strategies for two-sided markets. Harvard Business Review, 84(10), 92-101.

Evans, D. (2009). How catalysts ignite: The economics of platform-based start-ups. In A. Gawer (Ed.), Platforms, markets and innovation. Cheltenham: Edward Elgar. 
Khanna, T., \& Palepu, K. (2010). Winning in emerging markets. Harvard: Harvard Business Press.

Moraa, Hilda. 2015. A Kenyan Startup Journey: My 10 Key Lessons.

Rochet, J.-C., \& Tirole, J. (2003). Platform competition in two-sided markets. Journal of the European Economic Association, 1(4), 990-1029.

TechMoran. (2015). Cellulant using mobile wallets to empower farmers across Africa. Afk Insider. http://afkinsider.com/107707/cellulant-using-mobilewallets-to-empower-farmers-across-africa/. Accessed 15 Jan 2016.

The World Bank. (2015). Doing business 2016: Measuring regulatory quality and efficiency. Washington, DC: The World Bank.

Wakoba, S. (2015). Kenya's Sendy creating a network of couriers to open up business in Nairobi. TechMoran. http://techmoran.com/kenyas-sendy-maps4m-data-points-open-nairobi-business/\#sthash.WvqfpW7q.dpbs. Accessed 15 Jan 2016.

White, B. (2015). On-demand package delivery, Sendy closes deal with Safaricom Spark Venture Fund. VC4Africa. https://vc4africa.biz/blog/ 2015/12/22/on-demand-package-delivery-sendy-closes-deal-withsafaricom-spark-venture-fund/. Accessed 15 Jan 2016.

Whole Foods Market. (2016). Information for potential suppliers. Whole Foods Market. http://www.wholefoodsmarket.com/company-info/informationpotential-suppliers. Accessed 15 Jan 2016.

World Economic Forum. (2014). The global competitiveness report 2015-2016: Full data edition. Geneva: World Economic Forum.

Zwillenberg, P., Field, D., \& Dean, D. (2014). The connected world: Greasing the wheels of the Internet economy. Boston: Boston Consulting Group. 


\section{Conversation \#4}

\section{Finding the Right Problem to Solve}

\section{Timbo Drayson of OkHi}

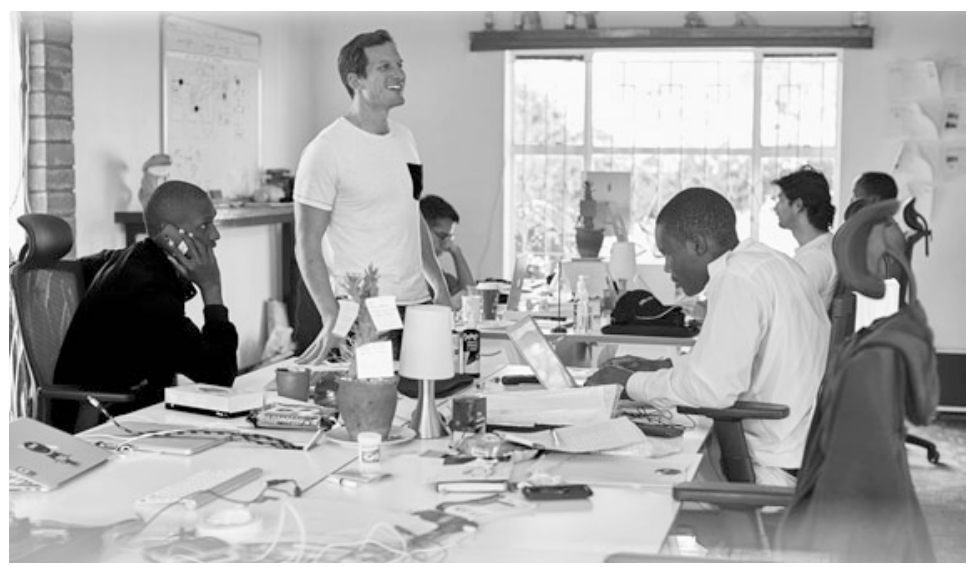

Timbo Drayson is co-founder and chief executive officer (CEO) of OkHi, a start-up based in Nairobi whose mission is to enable the four billion people in the world without a physical address to "Be included." Born in the UK, he studied engineering at the University of Oxford before starting at Google, where he spent more than six years working in marketing and product management in London and San Francisco. He built the YouTube apps on your mobile phone, marketed the first Android phone, and has seven US patents to his name. Outside of work, Timbo wastes his time fixing up his VW camper van or doing some form of exercise to keep his mind sane. 


\section{What is the story behind OkHi?}

Well, I was supposed to be moving to San Francisco for a dream job at YouTube but decided to take a three-month sabbatical before I sold my soul to Silicon Valley. I did a tech tour of Sub-Saharan Africa and was inspired by all the start-ups I met that were impacting the world through their profitable businesses. Realizing it was now or never, I left Google in mid-2013 to move to Kenya to have a better chance at solving a bigger problem.

I chose Kenya because it just felt right. I loved my time in Nairobi because of the amazing people I met, the lack of language barrier, the exciting tech community, and ultimately because I felt I could live a happy and integrated life as an expatriate.

As for how OkHi started, an important learning from my previous start-up was that it is not the idea that counts, it is the underlying problem that you need to focus on. I therefore purposely arrived in Kenya with no business ideas but spent three months trying to find the right problem to solve. I settled on the lack of physical address system in Kenya and beyond.

\section{Did you explore the problem all on your own or did you look for co-founders?}

During my three months of research, I spent all day meeting new people and was always looking for co-founders who could complement my skill set and provide local Kenyan insights into the business. It was at an event called Startup Weekend that I met Wes Chege and Evans Mutai, and soon after I was introduced to Navraj Ghataura by a common friend in the tech community (thanks, Adam!). We were all interested in the problem of physical addressing, and so, we started working together in early 2014 to validate how big the problem was and whether businesses would pay for a solution.

Since then we have had Henry Ingham, Punit Shah, Dennis Mutugi, and Mugethi Gitau join the team, all from very different backgrounds and experience, but all passionate about our mission to make the four billion people in the world without an address "Be included." 
You mentioned that you are all passionate about OkHi's mission. What do you have in mind when you refer to a mission?

I am sure there are many definitions out there, but for me, a missiondriven business is one that focuses on solving a big problem. My previous start-up is a good example of what happens when you focus too much on a solution, and not the problem or mission. We had this idea for a service that could pool money from a group of friends to enable them to buy a better gift for a mutual friend. We were really obsessed with the idea and spent every hour outside of our day jobs working on it. After 18 months of tireless work we launched, but no one came. We tried to make it work, but we were so demotivated that we had to shut down the business.

My main learning was that our business was far too focused on the idea. This meant that when the idea didn't work, we had no reason to continue running the business. If, however, we focused on the underlying problem, even if the initial idea didn't work, the problem would still be there and so too would the reason to continue running the business.

That is the point of being a mission-driven company: The underlying problem remains unchanged and constantly keeps the team challenged and motivated to find the right solution.

\section{How did you find out just how big the problem is that OkHi seeks to solve? And how did you turn that into a mission statement?}

So there are two parts to this. One is, how did I settle on the right problem? And two is, how did we come up with our mission statement to "Be included"?

During my research phase, I chose the logistics and supply chain space as my broad problem area because I saw that its inefficiencies were having such a detrimental impact on the economy and anyone living in Kenya. I spent three months interviewing 120 people and observed a number of businesses in order to find the right problem to solve. I observed van drivers taking crazy routes and motorbike riders having to follow crazy directions like "Turn left where the goats used to graze." It was after all these insights that I realized that the lack of a physical address system was 
one of the most fundamental reasons for the inefficient logistics and supply chain industry.

There were two further insights that told me this was the right problem to solve. First, during an interview with a Red Cross ambulance driver, she told me that she was so lost trying to find someone's house that when she arrived it was too late, and the person was already dead. This made me realize that the problem of physical addressing was so much bigger than just the logistics and supply chain industry. The second insight was from a United Nation (UN) spokesman, who said there were four billion people in the world without a physical address today and that this number would double to eight billion by 2050 . That was when I realized quite how big this problem is for the world and that finding the right solution for it would be a mission that I wanted to dedicate the next decade or more of my life to.

The last step was to turn the problem into a single mission statement that inspired not only the team but also anyone who touched $\mathrm{OkHi}$, from friends to journalists, family members to prospective employees. It actually took us 18 months to come up with our current statement. At our first offsite retreat, we spent time trying to answer why OkHi needs to exist and why it is so important to solve the physical addressing problem. We settled on an initial statement that was to "physically connect the world with a global address system." Over time, though, it became clear that the statement was not inspiring enough, or emotional enough, so recently, we worked hard to revise it to something more human and aspirational. And that is what our mission statement is today, to "Be included." What do we mean by that? Well when someone gains a physical address, their life changes; they can now get access to emergency and finance services that they could not otherwise get access to. They are now part of society. They are now included.

As a side note, it often feels like certain elements of a company need to be $100 \%$ right from day zero, such as the mission statement and values. A big learning from building $\mathrm{OkHi}$ is that it is much better to make a quick decision that is $80 \%$ right than to worry about the last $20 \%$ and potentially never make the decision at all. 


\section{If the mission is the kernel of your venture, how do you select new team members? Let us imagine you selected me: What do you think I would find surprising in my first week on the job?}

It is funny-I do not think our hiring process is all that conventional. But judging by the caliber of the team, it seems to be working. As an example, I have not seen the CV for a single one of the seven OkHi team members. I do not even know how old everyone is!

Our hiring process is based on three principles. First, we hire for aptitude, not experience. Someone's aptitude is their natural ability to do something - it is in their DNA. This is much more important in a fast-changing start-up where responsibilities often change than someone who can only do one thing very well because that is all they have known for five years.

However, aptitude is very hard to test in an interview. So we test it through our second principle, which is to trial the candidate before making an offer. This is designed to be a two-way benefit — as much for the candidate to work out if OkHi is right for them as it is for us to test their aptitude and ability to exceed the expectations of their role.

The last principle is that we hire for cultural fit, meaning that we test a candidate on how well they align with our company values. This is often a deal breaker for me. For example, if a candidate does not align with our company value to "Grow together"-which means they need to be motivated to give and take feedback - then it does not matter how high their aptitude is, working at $\mathrm{OkHi}$ is not going to work out for us and, more importantly, for them.

To answer your other questions: In your first week, you would not find anything surprising, because you would have already spent enough time working at OkHi during your trial! And what makes OkHi special is definitely the team. They are the foundation of the company. It is incredible the power that comes from bringing a group of people together who are all aligned on the same company mission and values. 


\section{You and your team are strong advocates for the lean start-up mental- ity. Why is that?}

"Find a problem, not a solution" — which I have already mentionedis actually part of the lean start-up mentality. I think it really resonated with all of the co-founding team because we had all run companies before and had all made similar mistakes. These mistakes could be attributed to the fact that we made wrong assumptions. We assumed that our thoughts or ideas were right — until we were proven wrong. This is really the fundamental principle of the lean start-up: You are wrong until proven right.

When you are starting a business, you are trying to get to a point of success with the minimal cost possible, whether that cost is financial, your time, or otherwise. The Lean Start-up's mantra is that you do this through an iterative loop of Build, Measure, and Learn. You build something quickly that can test your assumptions, which is called the minimum viable product, or MVP. You then measure the success of this MVP in a qualitative or quantitative way, learning from what worked and what did not. And then you restart the loop again.

I wish I had known about the Lean Start-up during my previous startup, because it was only after 12 months of engineering that we learned our users did not understand our homepage. If we had put paper screenshots ("Build") in front of our target users ("Measure"), then we would have realized that no one understood our homepage in 2 weeks rather than 12 months ("Learn"). Though to be honest, the theory is the easy part. The hard part is putting the theory into practice, because there are so many open questions you need to answer. For example: Do we build one product or three different ones? What design fidelity should we build the product to? And, How many users do we need for the results to be statistically significant?

These questions highlight the many potential pitfalls of implementing a Lean Start-up, and the frustrating thing is that there is no right answer. Each company is so unique that you need to work out the right recipe yourself. Ironically, my best advice is to use the Build, Measure, 
Learn principles of the Lean Start-up to implement it successfully. In every work sprint, we define the process of how we are going to work ("Build"). Then after the sprint, the whole team reviews how it went ("Measure"). And then, we discuss why some things worked and some did not ("Learn"). If you do this enough times, you will generate a process for running the Lean Start-up principles that is optimized to your business, team, and culture.

\section{An entrepreneur is often seen as the individual hero that develops innovative solutions for long-lasting problems. How much is the entrepreneur really that lonesome fighter as opposed to a function of a wider community effort?}

From both working at Google and running OkHi, I have come to realize that every successful business is like an iceberg. I think everyone is guilty of seeing a company that has been successful with just a simple idea and thinks, "Why didn't I think of that?" or even worse "Wait, I had that idea - they stole my idea." But as someone who knows nothing about that business, all you can see is the tip of the iceberg above the water, the working solution. As soon as you start understanding more about the business, you realize there is so much more to it than you originally thought. Whether it is that they made a big pivot one year into the business (Twitter), had to fire one of the early co-founders (Facebook), or ran out of money and had to sell cereal boxes to make ends meet (Airbnb), every business has so much more to it below the surface.

So what I am saying is that it is never just the CEO or co-founders that make the business, it is the whole ecosystem around the business, from the employees to the partners, from the investors to the customers. Especially in the technology sector, the wider community is a hugely important factor to the success of the business, and it is often overlooked because it is one of the parts of the iceberg that remains under the water.

While I was at Google, I spent two years leading Google's developer outreach efforts across Europe, Middle East, and Africa and gained a unique perspective on seeing what was a small technology community in London in 2008 turn, in just five years, into one of the largest tech 
ecosystems in the world. There is no way the successful companies coming out of London today could have done so back in 2008, because there was not the capital, the mentors, or employees to make it happen. There just was not the ecosystem, or community.

For me, the biggest thing I see missing in Kenya is the lack of this kind of community. There is an amazing buzz here, but as entrepreneurs (and I include myself here), we do not do a good enough job of sharing, learning, and generally making the most of each other. We also lack the experience in Kenya of tech entrepreneurs who have built successful businesses multiple times. It is these people who are the ideal mentors, with vital advice for those of us who are inexperienced founders.

So it is up to us founders to actively make this change, to run and host local events ourselves, and forge relationships with more advanced ecosystems like Silicon Valley. It is happening_and will happen. It is just up to us as entrepreneurs how much fuel we want to put into the local tech ecosystem fire. I think we need a lot more!

\section{Let us imagine you could start OkHi all over again. What would you change?}

This is a tough one. There are so many things! I suppose thinking through the timeline of $\mathrm{OkHi}$, I would say the following:

First, I would find a co-founder who could run the operations of the business. There is a lot of company infrastructure to build as a start-up, especially in Kenya, where you cannot yet buy solutions off the shelf to set up your payroll, benefits package, or stock option plan. It takes time to get it right, especially because I was doing this in a new country. Operations is also not a strength of mine, so I spent a lot of time doing it when it would have been better for me to focus on other areas of the business.

Second, I would solidify the values of the company early on. As a team we have spent time talking about our values, doing exercises to understand what our personal values and therefore our company values 
should be. But it took me almost two years to clearly define a set of values, because I put so much onus on them that I was scared of not getting them $100 \%$ right. This was actually where I learned the importance of making a decision, even if it is only $80 \%$ right. Now we have a set of five company values that the whole team is proud of (you can find them on our website), and they have really helped me, and the team test culture alignment in interviews, make decisions internally, and know how to act when talking to potential customers. They have become our internal compass.

The third would be to complement raising smart money with just money. Smart money is investment in your business that adds value beyond the money itself-things like mentorship, for example. Our first round of financing took over five months to close because I would not accept money from an investor unless it was smart money. In hindsight though, there should have been a balance.

The last thing I would have done differently would be to leverage mentors and investors more. It is very hard when you are in the weeds of running a business and trying to plow through the next wall ahead to take a step back and gain the perspective you need to steer the ship in the right direction. This is the support that great mentors and investors can provide - support that I need more of and support that I need to do a better job of getting.

\section{Thanks, Timbo!}

\footnotetext{
This chapter is distributed under the terms of the Creative Commons Attribution 4.0 International License (http://creativecommons.org/licenses/by/4.0/), which permits use, duplication, adaptation, distribution and reproduction in any medium or format, as long as you give appropriate credit to the original author(s) and the source, provide a link to the Creative Commons license and indicate if changes were made.

The images or other third party material in this chapter are included in the work's Creative Commons license, unless indicated otherwise in the credit line; if such material is not included in the work's Creative Commons license and the respective action is not permitted by statutory regulation, users will need to obtain permission from the license holder to duplicate, adapt or reproduce the material.
} 